\title{
CARACTERÍSTICAS DA COMUNICAÇÃO EM INDIVÍDUOS COM A SÍNDROME DO X FRÁGIL
}

\author{
Sueli Mami Yonamine ${ }^{1}$, Ariovaldo Armando da Silva ${ }^{2}$
}

\begin{abstract}
RESUMO - O objetivo deste estudo foi, a partir da avaliação de linguagem de um grupo de 10 meninos com idades variando entre 6 e 13 anos e com a síndrome do cromossomo X frágil (SXF), caracterizar o nível de comunicação desses indivíduos a partir de escalas de desenvolvimento normal. Constatou-se que dentro desta amostra, os indivíduos apresentaram predominantemente forma de comunicação linguística (80\%), atingindo o nível máximo de até 3 anos de idade. Concluiu-se que os dados obtidos confirmam o significativo atraso na aquisição e desenvolvimento da comunicação, necessitando, portanto, de intervenção precoce e especializada.
\end{abstract}

PALAVRAS-CHAVE: síndrome do X frágil, fala, linguagem, comunicação.

\begin{abstract}
Characteristics of the communication in individuals with fragile $X$ syndrome
ABSTRACT - The aim of this study was to make a characterization of the communication in a group with fragile $X$ syndrome (FXS), based on normal development scale. The sample has 10 boys, between 6 and 13 years and with FXS. All of them were submitted to language evaluation. The most part of them had the communication in linguistic form (80\%), until 3 years old. It was considered that the data confirmed the significant delay in the acquisition and development of the communication, being necessary an early and specialized intervention.
\end{abstract}

KEY WORDS: fragile $X$ syndrome, speech, language, communication.

Nos últimos anos, a síndrome do $X$ frágil (SXF) vem merecendo grande atenção não apenas por sua prevalência, mas também pelas peculiaridades desua transmissão e pelos distúrbios de desenvolvimento a ela associados. Atualmente, sua prevalência é de 1:2500․ Em estudos mais recentes baseados em revisão de diagnósticos citogenéticos, utilizando métodos de análise molecular, estima-se prevalência de 1:4000-6000². É considerada a principal causa hereditária e a segunda etiologia genética de retardo mental, sendo, nessa situação, somente superada pela síndrome de Down ${ }^{1,3}$.

O indivíduo com SXF apresenta considerável dificuldade em se comunicar. Em vista do atraso no desenvolvimento da linguagem, o objetivo deste estudo é caracterizar a comunicação de um grupo de indivíduos com SXF. Sabe-se que, além desta dificuldade, os indivíduos com SXF também apresentam anomalias físicas e comportamentais. Assim, serão considerados os principais aspectos da SXF.
Aspectos citogenéticos e moleculares da síndrome do $X$ frágil

A denominação de SXF relaciona-se à presença de uma região de fragilidade, mais sujeita à ocorrência de quebras ou falhas, ou um sítio frágil [fra(X)], localizado na porção distal do braço longo do cromossomo X, mais especificamente em Xq27.3. Essa característica pode ser verificada pelo exame de cariótipo, desde que seja utilizada técnica específica para a pesquisa de sítios frágeis, situando-se em torno de $4 \%$ o percentual limite para que o resultado da análise citogenética seja considerado positivo ${ }^{4}$. Essa fragilidade cromossômica não éa causa, mas a expressão citogenética da mutação de um gene localizado nessa região.

O gene, cuja anomalia funcional vincula-se ao fenótipo anômalo, foi designado FMR-1 (Fragile $X$ Mental Retardation). O FMR-1 tem 38 quilobases (kb) e 17 exons, havendo, no primeiro deles, uma região

Departamentos de Oftalmo-Otorrinolaringologia e de Genética Médica da Faculdade da Ciências Médicas (FCM) da Universidade Estadual de Campinas (UNICAMP), Campinas SP, Brasil: ${ }^{1}$ Fonoaudióloga, Mestre em Ciências Médicas; ${ }^{2}$ Professor-Assistente Doutor em Otorrinolaringologia do Departamento Oftalmo-Otorrinolaringologia.

Recebido 11 Fevereiro 2002, recebido na forma final 22 Maio 2002. Aceito 5 Julho 2002.

Dra. Sueli M. Yonamine - Rua Itapiru 465/132 - 04143-010 São Paulo SP - Brasil. E-mail: suelimy@ hotmail.com 
polimórfica de repetições de trinucleotídeos CGG que não é transcrita. Essa alteração caracteriza uma nova classe de mutações, designadas como dinâmicas pela ocorrência da expansão dessa sequência CGG ao longo de algumas gerações. Essa região representa a base molecular do sítio frágil, cuja expressão citogenética parece depender da multiplicação das trincas CGG ou, melhor dizendo, do comprimento desse elemento instável, o que também atuaria na modulação do quadro clínico 5 .

A mutação da SXF, representada genotipicamente como FRAXA ${ }^{5}$, ocorre em pelo menos dois passos. Nas pessoas normais, o cromossomo $X$ contém um número variável, porém estável, de sequências repetidas CGG, envolvendo, em média, entre 10 e 50 pares de bases. Quando o número de repetições aumenta para uma proporção da ordem de 50 a 200, o indivíduo, ainda sem manifestações clínicas, é considerado portador da pré-mutação. Na passagem pela ovogênese, deverá aumentar em tamanho, chegando a atingir cerca de 200 a 2000 cópias, caracterizando a mutação completa. O produto do gene FMR-1 é uma proteína (FMRP) cuja função não está esclarecida, mas se liga ao RNA e é capaz de transitar entre núcleo e citoplasma, estando presente em diferentes tipos de células, incluindo as cerebrais ${ }^{1}$.

Cerca de $20 \%$ dos homens identificados como transmissores da mutação FRAXA, com base na análise genealógica, são clinicamente normais. Tais indivíduos, possuem a pré-mutação e a transmitem a todas as suas filhas, igualmente assintomáticas mas a nenhum de seus filhos. Os genes pré-mutados são meioticamente instáveis e a sequência repetida se expande, chegando à mutação completa, a partir da gametogênese feminina. Assim, entre os netose netas de um homem transmissor normal é que haverá risco de ocorrência da SXF. Por conta disso, ao contrário de outras entidades com herança ligada ao sexo, as mães de indivíduos afetados sempre são consideradas portadoras obrigatórias, pois não existem casos diretamente resultantes de mutações novas ${ }^{1}$.

O diagnóstico definitivo da SXF depende da constatação da mutação FRAXA por estudo molecular. O exame de cariótipo pode ser útil e, em muitos centros, é o único recurso disponível como rotina de investigação, mas é um procedimento sujeito a faIhas, tanto com resultados falso-positivos quanto negativos. É oportuno lembrar que, na solicitação desse exame, deve ser mencionada a necessidade de técnica específica para pesquisa de sítios frágeis, pois a expressão do $\mathrm{fra}(\mathrm{X})$ depende do uso da mesma ${ }^{6}$.
Características físicas e comportamentais na síndrome do X frágil

A manifestação clínica mais importante é o retardo mental que, entre os homens, costuma ser grave (QI entre 20 e 35) ou, predominantemente moderado (QI entre 35 e 50) e leve ou limítrofe em cerca de um terço das mulheres. Além do comprometimento intelectual, outros sinais podem contribuir para o diagnóstico clínico da SXF, tais como dismorfismos faciais (face alongada e mandíbula proeminente), anomalias de pavilhão auricular (grandes e /ou em abano), além de macrorquidia (aumento do volume testicular), que não são obrigatórios e costumam se tornar mais evidentes a partir da puberdade ${ }^{5}$.

Sobre o desempenho intelectual, existem estudos que visam caracterizar a evolução do QI conforme o diagnóstico etiológico. Indivíduos com síndrome de Down, por exemplo, costumam mostrar um aumento lento do QI com o passar do tempo, porém ocorre uma estabilização na adolescência. No caso de homens com a SXF, demonstrou-se declínio nos resultados, sendo o período mais marcante o início da puberdade (11 a 15 anos), sugerindo a existência de processo degenerativo contínuo ${ }^{7,8}$.

Verificou-se ainda que mulheres com SXF costumam apresentar comportamento anormal, semeIhante ao dos homens em termos de qualidade, mas com grau de comprometimento inferior, possivelmente pela diferença no QI8.

As manifestações comportamentais dos indivíduos com SXF assemelham-se ao autismo, como a hiperatividade, o déficit deatenção, a dificuldade na interação social, a timidez, a ansiedade, a labilidade emocional e os movimentos estereotipados de mãos. Foi constatado que existe associação do autismo com a SXF que, entretanto, é casual e não causal. Não é raro que indivíduos com SXF tenham diagnósticos iniciais de autismo ${ }^{9}$, conformeobservado em vários estudos ${ }^{10-14}$.

\section{Aspectos da fala e da linguagem}

na síndrome do $X$ frágil

Na literatura referente a SXF pode-se constatar que distúrbios de fala e de linguagem são aspectos consistentes na descrição de indivíduos com SXF.

$O$ atraso na aquisição de fala é aspecto muito evidente na $\mathrm{SXF}^{15}$. Assim, na faixa etária até 12 anos, pode-se encontrar indivíduos com SXF na primeira etapa de comunicação ou nível pré-linguístico ou na segunda etapa ou primeiro nível linguístico. Acima de 12 e até 34 anos, há número significativo de indivíduos em etapas iniciais da comunicação oral ${ }^{16}$. 
Tabela 1. Comunicação pré-linguística.

\begin{tabular}{ll}
\hline Idade & Nível de comunicação \\
\hline 0-2meses & $\begin{array}{l}\text { Comunicação não intencional reativa: criança não apresenta nenhum comportamento de comunicação junto ao } \\
\text { adulto. Adultos atribuem significados ao comportamento da criança. A criança reage ao ambiente, em vez de } \\
\text { agir sobre ele. } \\
\text { 2-8 meses }\end{array} \quad \begin{array}{l}\text { Comunicação intencional pró-ativa: criança atua sobre o meio dando indícios mais claros de seus desejos, apro- } \\
\text { ximando-se das pessoas e objetos, pegando objetos. Os adultos interpretam o comportamento ativo da criança } \\
\text { c-12 meses }\end{array} \quad \begin{array}{l}\text { Comunicação intencional elementar: criança comunica-se intencionalmente com o adulto através do uso de } \\
\text { como agentes, utilizando-se de sinais simples para agir sobre os outros. }\end{array}$ \\
\hline
\end{tabular}

Tabela 2. Comunicação linguística.

\begin{tabular}{ll}
\hline Idade & Nível de comunicação \\
\hline 1 ano e 6 meses - 2 anos & $\begin{array}{l}\text { criança verbaliza em direção ao adulto ou objeto, podendo vir acompanhado de gestos. Nesta fase, a } \\
\text { criança utiliza-se de palavra-frase ou palavra justaposta para se comunicar. }\end{array}$ \\
2 anos - 2 anos e 6 meses & $\begin{array}{l}\text { criança comunica-se através da forma lingüística convencional, utilizando-se de frases simples, flexões } \\
\text { do substantivo e do verbo, além de artigos. }\end{array}$ \\
& $\begin{array}{l}\text { criança comunica-se através de frases simples com uso de sintagmas nominais e verbais, faz perguntas, } \\
\text { usa frases negativas, faz transformações na frase ouvida, há incorporação de preposições, conjunções, } \\
\text { desinências de gênero, número e pessoa, aumento de vocabulário, proporcionando ampliação da sinta- } \\
\text { xe e semântica. }\end{array}$ \\
\hline
\end{tabular}

Tabela 3. Distribuição dos indivíduos, segundo forma de comunicação.

\begin{tabular}{lcr}
\hline Nível de comunicação & Número de pacientes & $\%$ \\
\hline Prélinguístico & 2 & 20 \\
Linguístico & 8 & 80 \\
Total & 10 & 100 \\
\hline
\end{tabular}

A habilidade em linguagem em homens jovens, com idade entre 6 e 17 anos com SXF, evolui até atingir aproximadamente a idade de 3,2 anos ${ }^{17}$.

Observam-se na fala de indivíduos com SXF algumas manifestações frequentes, como ecolalia e perseveração ${ }^{15,18-20}$. Tais manifestações são caracterizadas como fala com repetições de expressões e/ ou frases, ou ainda, ininterrupta e inapropriada sobre um mesmo assunto, a fim de aumentar o prazo para a elaboração da resposta, na tentativa de encontrar o que deveria vir a seguir, uma palavra ou uma frase, para estabelecer estrutura sintática que permitisse a sustentação do diálogo ${ }^{20}$.

Ainda é frequente encontrar-se na fala de indiví- duos com SXF, distúrbios sintáticos e inconsistência no quadro fonético-fonológico ${ }^{16,22,23}$, além de dificuldade em sequencializar movimentos; os dois últimos itens caracterizam o quadro de apraxia fonoarticulatória em indivíduos com SXF18, 23.

A fala na SXF é ser comumente caracterizada como rápida e disfluente. O indivíduo pode também apresentar hesitação em falar e suas palavras e frases podem ser entrecortadas ${ }^{19}$.

Os aspectos cognitivos encontram-se alterados nos indivíduos com SXF, pois apresentam alterações perceptuais auditivas e visuais ${ }^{16}$, tais como discriminação e memória imediata e de curto prazo ${ }^{17,24}$. Essas dificuldades, somadas às alterações no desenvolvimento neurológico, linguístico e das estruturas lógicas, acabam ocasionando quadro de dificuldade no aprendizado da comunicação gráfica ${ }^{16}$.

Os indivíduos com SXF apresentam não apenas déficits relacionados à sintaxe, mas também à semântica, como dificuldade de evocação de palavras e pouca habilidade em escolher a palavra correta do léxico mental ao tentar produzir um pensamento com significado e bem estruturado ${ }^{23,25}$. 
Tabela 4. Distribuição dos indivíduos com forma de comunicação pré-linguística, segundo escala de desenvolvimento normal de linguagem.

\begin{tabular}{lcc}
\hline Nível pré-linguístico & Número de pacientes & $\%$ \\
\hline 0 -2 meses: comunicação não intencional reativa & 0 & 0 \\
2 - 8 meses: comunicação não intencional pró-ativa & 0 & 0 \\
8 - 12 meses: comunicação Pré-linguística intencional elementar & 2 & 100 \\
Total & 2 & 100 \\
\hline
\end{tabular}

Tabela 5. Distribuição de indivíduos, segundo idade cronológica e nível de comunicação.

\begin{tabular}{ccc}
\hline Paciente & Idade cronológica & Nível de comunicação \\
\hline P4 & 6 anos & 8-12 meses \\
P6 & 7 anos & 2 anos - 2 anos 6meses \\
P8 & 8 anos & 2 anos -2 anos 6 meses \\
P7 & 10 anos & 1 ano 6 meses -2 anos \\
P1 & 10 anos & 2 anos -2 anos 6 meses \\
P9 & 10 anos & 2 anos 6 meses -3 anos \\
P2 & 12 anos & 2 anos 6 meses -3 anos \\
P10 & 12 anos & 2 anos 6 meses -3 anos \\
P5 & 13 anos & 8-12 meses \\
P3 & 13 anos & 2 anos 6 meses -3 anos \\
\hline
\end{tabular}

\section{MÉTODO}

Foram selecionados, aleatoriamente, 10 pacientes com idade entre 6 e 13 anos, com diagnóstico de SXF, com base no quadro clínico e na pesquisa citogenética positiva, pois no período em que foi realizado o estudo, o exame de cariótipo era o único recurso disponível na rotina de investigação. Em virtude disso, não foi possível realizar o estudo molecular da mutação FRAXA desses indivíduos. A conclusão diagnóstica clínica e laboratorial foi realizada no Departamento de Genética Médica - Faculdade de Ciências Médicas - Unicamp.

De agosto de 1999 a setembro de 2000, a avaliação de linguagem realizou-se com base na evolução comunicativa, considerando-se as escalas de desenvolvimento da comunicação normal26-28. As avaliações foram filmadas em fita VHS, para posterior análise das informações obtidas.

Considerou-se, inicialmente, a presença ou ausência de linguagem verbal, classificando-se os indivíduos avaliados em 2 grupos, segundo a forma de comunicação: prélinguística ou linguística.

Dentre os indivíduos com forma de comunicação prélinguística, considerou-se a escala que consta da Tabela 1. Com relação aos indivíduos com forma comunicativa linguística, considerou-se a escala a que consta da Tabela 2.
Na avaliação da linguagem dos indivíduos com SXF e com forma pré-linguística de comunicação, aplicou-se a lista de provas proposta pelo "Protocol for the assessment of prelinguistic intencional communication" 29 , que apresenta lista de situações que podem desencadear algum tipo de comunicação: oral ou gestual.

$\mathrm{Na}$ avaliação da linguagem oral em indivíduos com forma de comunicação linguística, utilizaram-se as provas de contexto pessoal (diálogo), história a partir de estímulo visual (uma figura representando uma situação) e a partir do estímulo visual em sequência (figuras sequencializadas de ações), segundo os objetivos propostos pelo Exame de Linguagem $\mathrm{TPIT}{ }^{30}$. Assim, pôde-se verificar a eficiência comunicativa de cada indivíduo avaliado, tanto em situação mais espontânea através do diálogo, como também, em situação de elaboração de discurso narrativo através das histórias.

Houve consentimento formal dos pais dos pacientes que participaram desta pesquisa através do termo de consentimento, que esclareceu todos os procedimentos que seriam realizados durante a avaliação fonoaudiológica, como filmagem, fotos, gravação em fita cassete, além de futura publicação dos dados obtidos. Também houve aprovação pela Comissão de Ética da Instituição onde este estudo foi desenvolvido.

\section{RESULTADOS}

Constam das Tabelas 3, 4 e 5.

\section{DISCUSSÃO}

A SXF como se pôde constatar, apresenta mais estudos que abordam caracterizações físicas, comportamentais, citogenéticas e moleculares do que os relacionados à linguagem.

Os estudos sobre a linguagem dos indivíduos com SXF mostram alteração significativa frente às outras características, pois são descritos consideráveis atrasos ou "déficits" na comunicação oral, mesmo em adolescentes e adultos, com idades entre 12 e 34 anos $^{15}$, que permanecem em etapas iniciais de comunicação. No caso daqueles com SXF que conseguiram desenvolver relativamente a fala, especialmente no aspecto sintático da linguagem, consta- 
tam-se manifestações como a ecolalia e fala perseverativa que demonstram a grande dificuldade em lidar com a linguagem.

Os resultados obtidos no trabalho confirmam os dados de literatura referentes ao considerável atraso na aquisição e desenvolvimento da comunicação em indivíduos com SXF.

Apesar de tratar-se de amostra restrita, observando a Tabela 5, onde se faz a comparação entre idade cronológica e nível de comunicação, constatou-se que os resultados sugerem a existência de sequência de evolução linguística máxima até 3 anos, conforme o aumento da idade cronológica de 6 a 13 anos. Tais resultados dependem do ambiente em que a criança está inserida, da estimulação que tem recebido e do comprometimento cognitivo de cada indivíduo.

Assim, ao se compararem os achados com os padrões de normalidade, verificou-se um distúrbio de linguagem significante pois, nessa faixa etária de 6 a 13 anos, nenhum indivíduo alcançou a primeira subetapa do $2^{\circ}$ nível linguístico de comunicação. Portanto, não foi característica desta população o conhecimento total das formas de organização sintática da gramática dos adultos, bem como do uso de adjetivos, advérbios, conceitos de tempo-espaço e nível fonético-fonológico completamente adquiridos.

Diante dos dados obtidos, confirma-se que pacientes com SXF apresentam notável atraso nos padrões de comunicação linguística, visto que se constatou que, entre a faixa etária de 6 e 13 anos, os indivíduos avaliados apresentaram comunicação prélinguística ou linguística, até o nível de 3 anos.

É importânte o diagnóstico precoce que permita uma intervenção terapêutica o mais breve possível, além de se poder realizar a orientação familiar quanto aos aspectos genéticos o mais precocemente possível.

Frente às alterações encontradas neste estudo, sugere-se que, nos processos terapêuticos para desenvolvimento da linguagem receptiva, ao se trabaIhar com pacientes com SXF utilizem-se frases simples, com vocabulário rotineiro e muito explicativo, além de pausas frequentes entre as frases. No caso de presença de ecolalia e considerando-se que tal manifestação tenha o intuito de sustentar um diálogo, sugere-se que se pare a conversa, contextualize-se a palavra ou expressão repetida, dando-Ihe significado. Diante disso, éindispensável que o terapeuta acredite que a criança com SXF possa, um dia, vir a falar, apesar desta patologia determinar menor capacidade para aquisição e desenvolvimento da linguagem.

\section{REFERÊNCIAS}

1. Kaufmann WE, Reiss AL. Molecular and cellular genetics of fragileX syndrome. Am J Med Genet 1999;88:11-24.

2. Turner $G$, Webb $T$, Wake $S$, Robinson $H$. Prevalence of fragile $X$ syndrome. AmJ Med Genet 1996;64:196-197.

3. Keenan E, Keane V, Ramsey L. Fragile X syndrome. Irish Med J 1993;86:94-96.

4. Jacky PB, A huja, Y R, Anyane-Yeboa K, et al. Guidelines for the preparation and analysis of the fragile $X$ chromosome in lymphocytes. AmJ Med Genet 1991;38:400-403.

5. Vries BBA, Halley KJJ, Oostra BA, Niermeuer MF. The fragile $X$ syndrome. J Med Genet 1998;35:579-589.

6. Jorde LB, Carey JC, Bamshad MJ, White RL. Genética médica. Rio de Janeiro: Guanabara Koogan, 2000:89-91.

7. Hodapp RM., DykensEM, Hagerman RJ, Scheriner R, Lachiewicz AM Leckman JF. Developmental implications of changing trajectories of IQ in males with fragile X syndrome. J Am Acad Child Adolesc Psychiatry 1990;29:214-219.

8. Reiss AL, Lee J, Freund L. Neuroanatomy of fragile $X$ syndrome: the temporal lobe. Neurology 1994;44:1317-1324.

9. Brown TW, Jenkins EC, Cohen IL, et al. Fragile $X$ and autism. Am J Med Genet 1986;23:341-352.

10. Turner G, Daniel A, Frost M. X-linked mental retardation, macroorchidism, and the Xq27 fragile site. Pediatrics 1980;96:837-841.

11. Proops $R$, Webb $T$. The fragile $X$ syndrome in the Martin-BellRenpenning syndrome and in males with other forms of familial mental retardation. J Med Genet 1981;18:366-373.

12. Meryash DL, Szymanski LS, Gerald PS. Infantileautism associated with the fragile X syndrome. J Aut Dev Disord 1982;12:295-301.

13. Levitas A, Hagerman RJ, Braden M, Rimland B, Mcbogg P. Autism and the fragileX syndrome. J Dev Behav Pediatr 1983;4:151-158.

14. Varley CK, Holm, V, Eren MO. Cognitiveand psychiatric variability in three brothers with fragileX syndrome. Devel Behav Pediatr 1985;6: 87-90.

15. Guerreiro MM. Síndrome do X frágil: características clínicas, eletrencefalográficas e de imagem. Tese UNICAMP, Campinas, 1993.

16. Giacheti CM. Achados Fonoaudiológicos em indivíduos com a síndrome do cromossomo X frágil. Tese, Escola Paulista de M edicina, São Paulo, 1992.

17. Fisch GS, Holden JJA, Carpenter NJ. et al. A gerelated languagecharacteristics of children and adolescents with fragile $X$ syndrome. Am J Med Genet 1999;83:253-256

18. Hanson DM, Jackson AW, Hagerman RJ. Speech disturbances (cluttering) in mildy impaired males with the Martin-Bell/ fragile $X$ syndrome. AmJ Med Genet 1986;23:195-206.

19. Paul R, Dykens E, Leckman MW, Breg WR, Cohen DJ. A comparison of language characteristics of mentally retarded adults with fragile $X$ syndrome and those with nonspecific mental retardation and autism. J Aut Dev Disord 1987;17:457-468.

20. Sudhalter V, Cohen IL,Silverman W, Wolf Schein EG. Conversational analyses of males with fragile $X$, Down syndrome and autism: a comparison of the emergence of deviant language. Am J Med Genet 1990;94:431-441.

21. Sudhalter V, Hollis S, Cohen I L. Syntatic delay and pragmatic deviance in the language of fragile X males. A mJ Med Genet 1991;38:493-497.

22. Howard-Peebles PM, Stoddard GR, Mims M G. Familial X-linked mental retardation, verbal disability and marker X chromosomes. AmJ H um Genet 1979;31:214-222.

23. Spinelli M, Rocha ACO, Giachtil C M, Richieri-Costa A. Word-finding difficulties, verbal paraphasias, and verbal dyspraxia in tem individual with fragile X syndrome. AmJ Med Genet 1995;60:39-43.

24. Cornish KM., Munir F, Cross G. Spatial cognition in males with fragile $X$ syndrome: evidence for a neuropsychological phenotype. Cortex 1999;35:263-271.

25. Sukhalter $V$, Maranion $M$, Brooks $P$. Expressive semantic deficit in the productivelanguage of males with fragileX Syndrome. AmJ Med Genet 1992;43:65-71.

26. Brown RW. A first language: the early stages. Cambridge: Harvard Univ Press, 1973.

27. Hopper R, Naremore R. Children's speech 2.Ed. New York: Harper \& Row, 1978.

28. Launay C. Distúrbios da linguagem, da fala e da voz na infância. São Paulo: Roca, 1989:17-31

29. Casby MW, CumpataJF. A protocol for the assessment of prelinguistic intentional communication. J Commun Disord 1986;19:251-260.

30. Braz HA, Pellicciotti HF. Exame delinguagem TIPITI. 3.Ed. São Paulo: Editora MNJ, 1988 